\title{
Monitoramento da precipitação efetiva em diferentes povoamentos florestais: estudo de caso na Floresta Nacional de Ipanema, Iperó-SP
}

\author{
Emily Tsiemi Shinzato ${ }^{1}$ \\ Esthevan Augusto Goes Gasparoro ${ }^{1}$ \\ Kelly Cristina Tonello ${ }^{2}$ \\ Carlos Alberto Martinelli de Souza ${ }^{2}$ \\ Roberta de O. A. Valente ${ }^{2}$ \\ ${ }^{1}$ Discente Eng. Florestal, Universidade Federal de São Carlos - campus Sorocaba \\ Rodovia João Leme dos Santos, Km 110 - SP-264, Bairro do Itinga \\ Sorocaba - São Paulo - Brasil, CEP 18.052-780 \\ emilyshinzato@hotmail.com, exthevan@hotmail.com \\ 2 Prof Universidade Federal de São Carlos - campus Sorocaba \\ Rodovia João Leme dos Santos, Km 110 - SP-264, Bairro do Itinga \\ Sorocaba - São Paulo - Brasil, CEP 18.052-780 \\ kellytonello@ufscar.br, roavalen@ufscar.br, camartinelli@ufscar.br
}

\begin{abstract}
The water, renewable resource, but finite, has been studied in many areas of knowledge, especially with regard to their availability on the surface. Other studies, however, are developed to identify how and how much is their participation in various stages of the hydrology cycle. Researchs that relates rain with the rain forest systems are examples of this. This paper aims to present the importance of determining the effective rainfall, and to study the influence of forest vegetation in the hydrological cycle in watersheds, as well as the present study that is being developed in the Floresta Nacional de Ipanema, in Iperó - SP. These studies collect information on understanding the distribution of water on vegetation in order to generate forms of management are technically feasible, facilitating the important decisions for the integrated use of watershed.
\end{abstract}

Palavras-chave: Eucalyptus sp., Pinus sp., throughfall, stem flow.

\section{Introdução}

A água é um recurso peculiar, não somente pela sua amplitude de utilização, mas também por ser um indicador ambiental da qualidade do solo, comumente, alterado pelo homem (Tonello et al., 2009). As águas dos cursos que drenam uma região apresentam características físicoquímicas próprias, que refletem o uso do solo, da respectiva bacia hidrográfica.

O termo bacia hidrográfica pode ser definido como a área de captação natural da água da precipitação, drenando essa água por ravinas, canais e tributários, para um curso d água principal, tendo a vazão uma única saída, desaguando em um curso dágua maior, lago ou oceano. A utilização da bacia hidrográfica como unidade de planejamento e gerenciamento ambiental não é recente. Há tempos os hidrólogos têm reconhecido as ligações entre características físicas de uma bacia hidrográfica e a quantidade de água que chega aos corpos hídricos. Por outro lado, os limnólogos têm considerado que as características do corpo d água refletem as características de sua bacia de drenagem. Neste sentido, as abordagens de planejamento e gerenciamento ambiental utilizando a bacia hidrográfica como unidade de estudo têm evoluído, desde que as mesmas apresentam características biogeofísicas que denominam sistemas ecológicos e hidrológicos relativamente coesos (Dasmann et al., 1973 citado por Pires et al., 2002).

O manejo de bacias hidrográficas corresponde ao processo que permite formular um conjunto integrado de ações ao ambiente, as estruturas sociais, econômicas, institucionais e legais 
de uma bacia, a fim de promover a conservação e utilização sustentável dos recursos naturais e desenvolvimento sustentável.

O planejamento ambiental por bacia hidrográfica, por outro lado, apresenta a vantagem de concentrar as ações numa área geográfica definida previamente com o auxílio de cartas topográficas e delimitada pelos divisores de água, de onde fluem as águas da chuva para as partes mais baixas do terreno, formando os cursos d'água. Nos limites das bacias estão as nascentes dos córregos que compõem junto com os rios, dos quais são tributários, o sistema de drenagem de uma determinada região. Assim, as intervenções ao nível da sub-bacia visam atenuar os impactos gerados pela ação humana nas cabeceiras dos rios, como forma de beneficiar tanto a população da área rural, quanto às populações das cidades, geralmente localizadas a jusante das bacias (Farah \& Barboza, 2000).

De acordo com Lima (2008) o importante é reconhecer que a bacia hidrográfica é uma unidade natural de planejamento de recursos naturais e, ainda, que a água é o agente unificador de integração no Manejo de Bacias Hidrográficas, baseado na sua vital e estreita relação com outros recursos naturais. O conhecimento da hidrologia, bem como do funcionamento hidrológico da bacia hidrográfica são, portanto, fundamentais para o planejamento e manejo dos recursos naturais renováveis, visando o uso auto-sustentável em bacias hidrográficas.

O estudo e a compreensão da distribuição da água na vegetação, principalmente a florestal podem gerar, dessa forma, formas de manejo tecnicamente viáveis, facilitando a tomada de decisões importantes para o uso integrado das bacias hidrográficas (Valcarcel, 1984).

Neste contexto, o objetivo do presente trabalho é estudar as alterações do uso e cobertura do solo sofridas em bacias hidrográficas e, em especial, qual a influência da vegetação florestal na qualidade e quantidade de água dessas bacias.

\section{A importância da precipitação efetiva no manejo de bacias hidrográficas}

A água, recurso renovável, porém finito, tem sido objeto de estudo de diversas áreas de conhecimento, principalmente no que se refere a sua disponibilidade na superfície terrestre. Outros estudos, porém, são desenvolvidos no sentido de identificar como e de quanto é sua participação em diversas etapas do ciclo hidrológico. As pesquisas que relacionam as chuvas relações com sistemas florestais são exemplos disto. Devido à sua capacidade de produzir escoamento superficial, a chuva é o tipo de precipitação mais importante para a hidrologia (Bertoni \& Tucci, 2001). A Região Sudeste sofre influência de sistemas tropicais e de latitudes médias com estação seca bem definida no inverno e estação chuvosa de verão, caracterizada pela alta freqüência de chuvas convectivas (Marengo, 2001).

A avaliação da retenção de água pelo dossel das florestas, é sem dúvida, importante para o conhecimento da fase do ciclo hidrológico em que parte do precipitado é evaporado e parte chega efetivamente ao solo. Adota-se, arbitrariamente, o início do ciclo a partir da evaporação da água da crosta terrestre com a incidência da energia solar e ventos sobre, principalmente, os oceanos, que são a principal fonte de água para a atmosfera. A água, ao evaporar, migra para as partes mais altas da atmosfera, acompanhando as correntes de ar quente, onde se condensa e forma as nuvens, que vão ficando cada vez mais densas até que se precipitam sob a forma de chuva. Ao atingir a superfície terrestre, as chuvas podem incidir sobre os oceanos e/ou continentes.

Nos continentes, a precipitação pode ser interceptada por diferentes coberturas: dossel das florestas, plantações agrícolas, superfícies impermeabilizadas (como ecossistemas urbanos), enfim, qualquer barreira que encontre antes de atingir o solo. Quando se trata de ecossistemas naturais ou implantados, denomina-se esta fase de interceptação. Uma outra fração da mesma 
precipitação que consegue atingir direta ou indiretamente a superfície do solo denomina-se de precipitação interna. Parte do que foi interceptado pelo dossel da floresta pode ser evaporada e outra parte pode ainda escoar pelos galhos e troncos das árvores até atingir o piso florestal formando a fração chamada de escoamento pelo tronco. Desse modo, a soma da fração de precipitação interna e a fração de escoamento pelo tronco tem como resultado, a fração da precipitação de chuva que realmente atinge a superfície do solo e que, hidrologicamente, é denominada de precipitação efetiva.

A precipitação efetiva pode ainda seguir outros caminhos, como escoar livremente pela superfície do solo até encontrar um caminho direcional como sulcos, ravinas, e cursos d'água. Porém, devido às características do piso de ecossistemas florestais, com grande proporção de matéria orgânica fornecida pela serrapilheira, juntamente com a porosidade dos solos, grande parte da precipitação efetiva tende a se infiltrar. A água infiltrada forma a umidade do solo, os aqüíferos, e ainda pode escoar até atingir um fluxo de água externo, como uma nascente ou diretamente um curso d'água.

Atingindo os cursos d'água estes vão formar a malha que drena a água da bacia hidrográfica. Cada bacia possui uma única saída para um rio principal que, geralmente, vai de encontro aos oceanos, fechando assim o ciclo hidrológico. Isto tem garantido as diferentes formas de vida em todas as partes do planeta.

O tipo de vegetação, seu estágio de regeneração e a área basal da mesma podem dar um indicativo do volume de água efetivamente precipitada na superfície da bacia hidrográfica (Tonello et al., 2004). A cobertura vegetal, através da precipitação efetiva, tem influência na redistribuição da água de chuva, onde as copas das árvores formam um sistema de amortecimento e direcionamento das gotas que chegam ao solo de forma mais suave e menos impactante, afetando assim, a dinâmica do escoamento superficial e o processo de infiltração, favorecendo o abastecimento dos mananciais subterrâneos. O tipo de vegetação caracteriza a quantidade de gotas que cada folha pode reter e a densidade da mesma indica o volume retido numa superfície de bacia.

Conforme apresentado anteriormente, a precipitação efetiva é composta pela precipitação interna, fração da precipitação que passa pelo dossel, e escoamento pelo tronco. Os fatores que interferem na precipitação interna podem estar ligados a características do clima como: lâmina d'água precipitada, intensidade da chuva, duração da chuva, freqüência dos eventos de chuva, espessura das gotas de chuva, intensidade, direção e duração do vento e temperatura.

A precipitação interna pode ainda ser influenciada por características do próprio ecossistema como o índice de área foliar da vegetação que recobre o solo, rugosidade das folhas, ângulo de inserção das folhas, profundidade do dossel, estrutura da floresta, composição de espécies, fitossociologia, densidade de plantas, espaçamento de plantio e topografia do terreno.

Em ecossistemas florestais, torna-se de suma importância o conhecimento quantitativo destas frações para que o balanço hídrico do ecossistema seja completo e os efeitos do desenvolvimento das florestas e estádios sucessionais sejam percebidos com êxito (Tonello et al., 2004).

Com relação aos valores de precipitação efetiva, observa-se uma grande variação entre os dados, parte devido aos fatores anteriormente discutidos. No entanto, verifica-se que o gênero Pinus apresenta variações mais acentuadas, quando observada de forma geral, a precipitação efetiva varia de 69,3 a 93,4 \% da precipitação fora do plantio florestal. Enquanto que no gênero Eucalyptus a precipitação efetiva varia de 85,7 até $89,2 \%$. Uma tendência que se observa é a 
diminuição da precipitação efetiva de chuvas com o aumento da idade, em princípio explicado pelo aumento da cobertura do solo pelo dossel.

Algumas pesquisas relatam que o escoamento pelo tronco é relativamente baixo em florestas naturais ou plantadas (Arcova et. al., 2003; Oliveira Júnior e Dias, 2005). Aldridge \& Jackson (1973) verificaram que o escoamento pelo tronco em uma floresta latifoliada na Nova Zelândia, só se manifestava em precipitações maiores que $1,3 \mathrm{~mm}$. Já um estudo realizado no Brasil em 1936, Geiger (1966) (citado por Lima, 1976), em uma floresta subtropical, relata que o escoamento pelo tronco representou $28 \%$ do total da precipitação incidente. Em povoamentos homogêneos de Eucalyptus saligna e de Pinus caribaea caribaea, Lima (1976) observou que o escoamento pelo tronco em relação a primeira espécie representou $4,2 \%$ da precipitação total - se manifestando apenas em precipitações acima de $2,5 \mathrm{~mm}$ - já na segunda espécie, o escoamento pelo tronco correspondeu à $3,0 \%$ dessa precipitação - presente apenas nas precipitações superiores a $4 \mathrm{~mm}$. $\mathrm{O}$ autor concluiu que os menores índices de escoamento pelo tronco nas coníferas está relacionada a sua maior rugosidade de casca.

Oliveira Jr. e Dias (2005) observaram uma precipitação efetiva (PE) do trecho da Mata do Paraíso no período de estudo, compreendido entre setembro de 2002 e maio 2003, foi de 849,6 $\mathrm{mm}$, correspondendo a $81,7 \%$ da precipitação no aberto (PA) igual a $1.039,5 \mathrm{~mm}$, em que a precipitação interna (PI) e o escoamento pelo tronco $(\mathrm{Et})$ contribuíram, respectivamente, com 80,0 e 1,7\%. Castro et al. (1983), realizando estudos de interceptação na mesma mata, mas em locais diferentes, encontraram PE igual a 87,6\% da PA, com valores de PI e Et igual a 87,4 e $0,2 \%$, respectivamente. As diferenças obtidas entre as duas avaliações podem ser devidas à metodologia, à própria condução do experimento ou, ainda, à amostragem. No entanto, os resultados indicaram também o efeito do fechamento e ingresso de espécies no dossel nesses 20 anos de diferença entre os dois trabalhos. Assim, a proporção de PI reduziu 7,4\% e o Et aumentou, 1,5\%. Resultado esse esperado, em razão avanço do estágio de regeneração do fragmento.observaram a precipitação efetiva (PE) do trecho da Mata do Paraíso no período compreendido entre setembro de 2002 e maio 2003, obtendo $849,6 \mathrm{~mm}$, correspondendo a 81,7\% da precipitação no aberto (PA) igual a $1.039,5 \mathrm{~mm}$, em que a precipitação interna $(\mathrm{PI})$ e o escoamento pelo tronco (Et) contribuíram, respectivamente, com 80,0 e 1,7\%.

Esses porcentuais, apesar de pequenos, devem ser considerados de grande importância, pois a quantidade e a baixa velocidade da água que chega ao solo, através do escoamento pelo tronco, facilita a infiltração. Para alguns autores, o Et funciona como um mecanismo de autoabastecimento que exerce efeito sobre a qualidade e quantidade de entrada de água no solo, resultante da distribuição localizada e significante ao redor dos troncos, principalmente durante o período seco (Johnson, 1990; Price, 1982; Huber \& Oyarzún, 1983) e ainda, um papel importante no regime químico e biológico do solo (Lima, 2008).

\subsection{Estudo de caso: Floresta Nacional de Ipanema, Iperó-SP}

A Floresta Nacional de Ipanema (FLONA de Ipanema, Figura 1) está localizada na Região Sudeste do Estado de São Paulo, a $120 \mathrm{~km}$ da capital paulista, entre as coordenadas $23^{\circ}$ $25^{\prime}$ e $23^{\circ} 27^{\prime}$ latitude sul, $47^{\circ} 35^{\prime}$ e $47^{\circ} 40^{\prime}$ longitude oeste, com altitudes variando de $550 \mathrm{~m}$ a 968 m. Seu território faz divisa entre os Municípios de Iperó, Araçoiaba da Serra e Capela do Alto (Regalado, 1999). A Flona Ipanema foi instituída pelo Decreto No. 530 de 20 de maio de 1992) e possui 5.179,93 hectares (cerca de $50 \mathrm{~km} 2$ ). De acordo com Radambrasil (1984), a vegetação da Floresta Nacional de Ipanema é caracterizada como área de transição (tensão ecológica) entre 
ecossistemas, tendo como principais formações vegetais a Floresta Estacional Semidecidual, o Cerrado e a Floresta Ombrófila Densa. Além das formações vegetacionais nativas do local, encontram-se ainda hectares de povoamentos de Eucalyptus sp e Pinus sp.

O clima da região de Ipanema pertence ao tipo "Cfa", ou seja, subtropical, mesotérmico úmido, sem estiagens, com estações chuvosas e secas bem definidas (Albuquerque, 1999). Precipitação média regional de $1.400 \mathrm{~mm}$, com mínimo de $800 \mathrm{~mm}$ e máximo de $2.200 \mathrm{~mm}$ (Souza \& Martos, 2008).

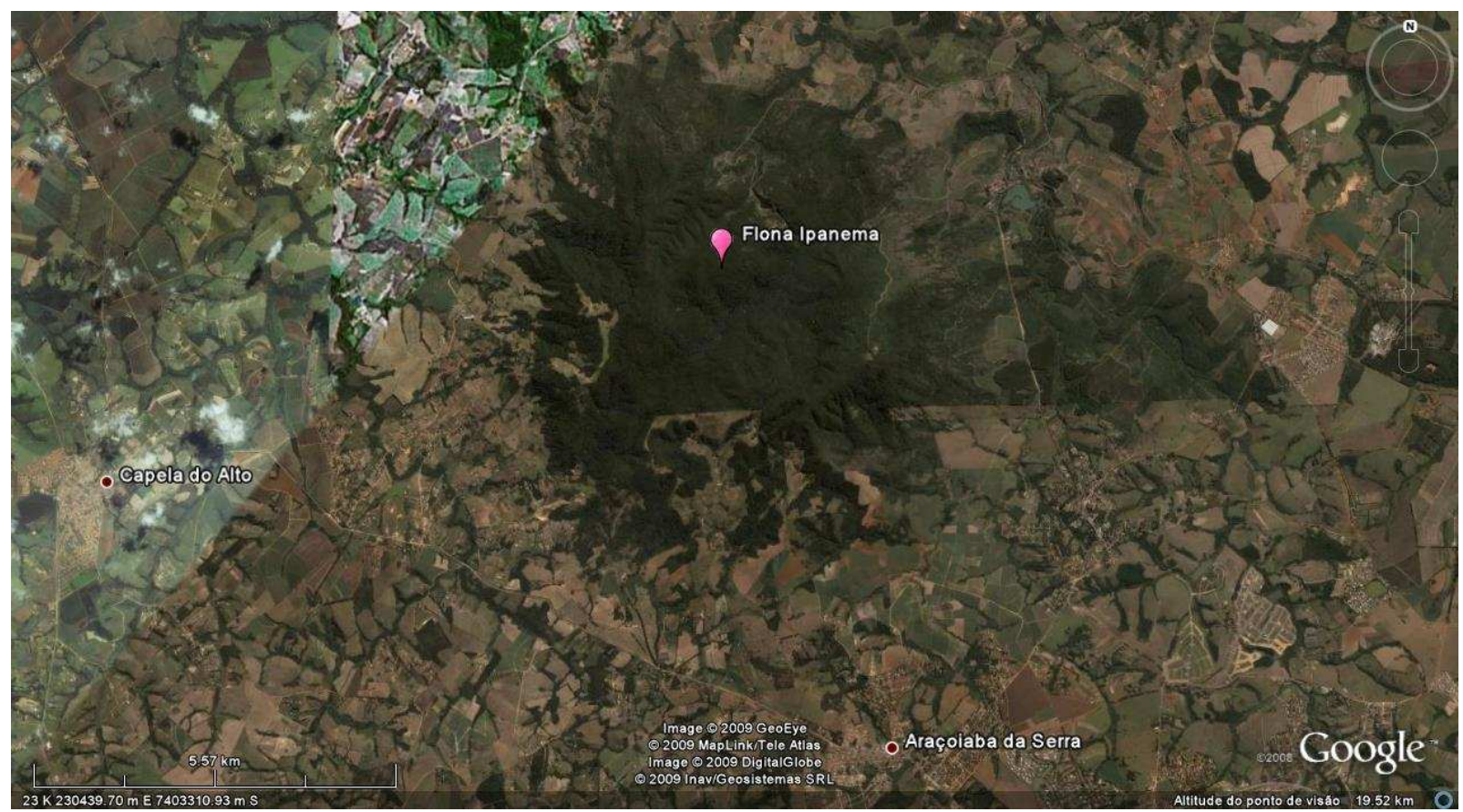

Figura 1. Localização da Floresta Nacional de Ipanema (FLONA Ipanema), Iperó-SP.

O monitoramento da precipitação efetiva está sendo realizado desde agosto de 2009 em povoamentos de Eucalyptus sp., Pinus sp. e Floresta Estacional Semidecidual. Os dados de precipitação a céu aberto são obtidos a partir de medições realizadas em 3 pluviômetros distribuídos próximos às áreas de estudo. Esses pluviômetros foram instalados em área aberta $\mathrm{e}$ fixados em estaca de madeira a $1,50 \mathrm{~m}$ da superfície do solo e o volume armazenado é quantificado por meio de uma proveta graduada. Para a quantificação do escoamento pelo tronco foram demarcadas três parcelas de 15 x $20 \mathrm{~m}$ (uma em cada povoamento). Em cada parcela foram adaptados coletores feitos a partir de pneu de bicicleta cortados em forma de calhas nos troncos das árvores com cap $\geq 15 \mathrm{~cm}$ (Figura 2a). A água escoada é direcionada para galões de plásticos e a leitura realizada com o uso de uma proveta graduada. A quantificação da precipitação interna está sendo realizada nas mesmas parcelas utilizadas para o monitoramento do escoamento pelo tronco. Em cada parcela foram instalados aleatoriamente 10 coletores mantidos fixos ao longo do período experimental (Figura 2b). 


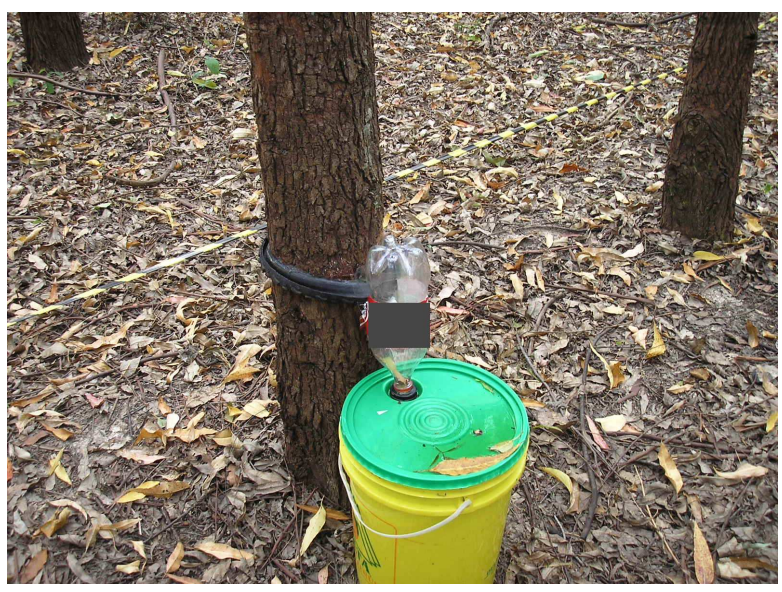

(a)

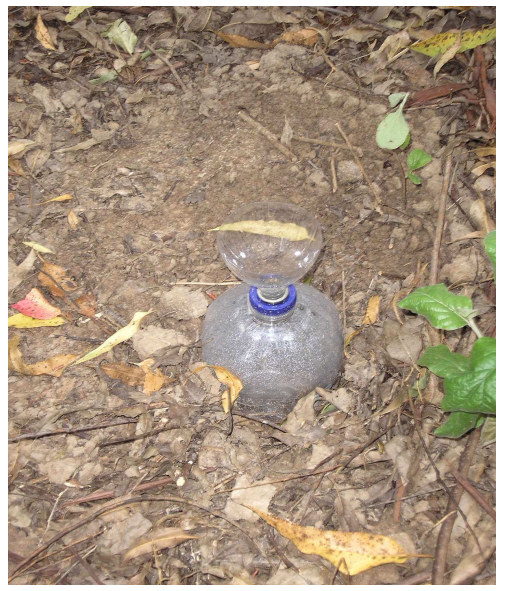

(b)

Figura 2. Monitoramento do escoamento pelo tronco (a) e precipitação interna (b) em povoamento de Eucalyptus sp.. Floresta Nacional de Ipanema, Setembro de 2009.

Como os três povoamentos aqui estudados encontram-se no mesmo sítio, espera-se conhecer a dinâmica da precipitação interna nos três povoamentos; observar as diferenças na precipitação interna nos três povoamentos; quantificar a influência destas espécies florestais no ciclo hidrológico local e contribuir com o treinamento de pesquisadores e bolsistas de iniciação científica na área de estudo.

\section{Considerações finais}

Um estudo comparativo entre estrutura e desenvolvimento de diferentes vegetações, capaz de considerar os fatores hidrológicos, é de relevante importância para um manejo adequado da flora, da fauna e de toda a bacia hidrográfica, gerando oportunidade para prever e entender a influência que a vegetação causa na precipitação interna, e ainda, criar medidas capazes de reduzir possíveis impactos adversos causados pela implantação de silviculturas e pelo manejo de florestas nativas. É ainda importante lembrar das implicações ecológicas da precipitação efetiva, como por exemplo, a entrada de nutrientes no ecossistema via água precipitada. Parte destes nutrientes são lixiviados da atmosfera e outra parte do próprio dossel e podem representar uma quantidade significativa para o crescimento e desenvolvimento da floresta.

\section{Referências Bibliográficas:}

ALBUQUERQUE, G. B. Floresta Nacional de Ipanema: caracterização da vegetação em dois trechos distintos do Morro de Araçoiaba, Iperó (SP). 1999. folhas. Dissertação (Mestrado em Ciências Florestais) - Escola Superior de Agricultura Luiz de Queiroz, Piracicaba, 1999.

ARCOVA, F.C.S.; CICCO, V.; ROCHA, P.A.B. Precipitação efetiva e interceptação das chuvas por floresta de mata atlântica em uma microbacia experimental em Cunha-SP. Revista Árvore, v.27, n.2, p.257-262, 2003.

BERTONI, J.C.; TUCCI, C.E.M. Precipitação. In. TUCCI, C.E.M.(Org.) Hidrologia: ciência e aplicação. 2.ed. Porto Alegre: Universidade Federal do Rio Grande do Sul, 2001. p.177-242. 
CASTRO, P.S. et al. Interceptação da chuva por mata natural secundária na região de Viçosa-MG. Revista Árvore, v.7, n.1, p.76-89, 1983.

FARAH, M.F.S.; BARBOZA, H.B. Novas Experiências de Gestão Pública e Cidadania. Rio de Janeiro: Editora FGV, 2000. 296 p. - (Coleção FGV Prática).

HUBER, A. J.; OYARZÚN, C. O. Precipitacion neta e interceptacion en un bosque adulto de Pinus radiata (D. Don.). Bosque, v.5, p.13-20, 1983.

JOHNSSON, R.G. The interception, throughfall and stemflow in a forest in Highland Scotland and the comparison with other upland forests in the U.K. Journal of Hydrology, v.118, p.281-287, 1990.

LIMA, W. P. Interceptação da chuva em povoamentos de eucalipto e de pinheiro. IPEF, Piracicaba, n. 13, p. 75-90, 1976.

LIMA, W.P. Hidrologia Florestal aplicada ao manejo de bacias hidrográficas. ESALQ/USP: Piracicaba, 2ed. 2008, 245p.

MARENGO, J.A. Variabilidade da Precipitação no Brasil. Ação Ambiental, v. 4, n.20, p.10-13, 2001.

PIRES, J.S.R.; SANTOS, J.E.; DEL PRETTE, M.E. A utilização do conceito bacia hidrográfica para a conservação dos recursos naturais. In: SCHIAVETTI, A. \& CAMARGO, A.F.M. (Ed.). Conceitos de Bacias Hidrográficas: Teorias e Aplicações. Ilhéus, Ba: Editus, 2002. p.17-35.

PRICE, N.W. A comparison of water balance components in natural and plantation forests in el Salvador, central America. Turrialba, v.32, p.399-416,1982.

OLIVEIRA JÚNIOR, J.C.; DIAS, H.C.T. Precipitação efetiva em fragmento secundário da Mata Atlântica. Revista Árvore, v.29, p. 9-15, 2005.

RADAMBRASIL - MINISTÉRIO DAS MINAS E ENERGIA/ DEPARTAMENTO NACIONAL DE PRODUÇÃO MINERAL. Projeto Radambrasil: Levantamento de Recursos Naturais. Folha Rio de Janeiro. Rio de Janeiro: DNPM/ Projeto RADAMBRASIL, 1984.

REGALADO, L.B. Composição e distribuição de aves passeriformes em uma parcela de mata do Morro de Araçoiaba (Floresta Nacional de Ipanema, Iperó/SP) utilizando um sistema de informação geográfica. 1999. FOLHAS. Dissertação (Mestrado em Engenharia Ambiental). Escola de Engenharia de São Carlos, São Carlos, 1999.

SOUZA, P.C.; MARTOS, H. L. Estudo do uso público e análise ambiental das trilhas em uma unidade de conservação de uso sustentável: Floresta Nacional de Ipanema, Iperó - SP. Rev. Árvore, Viçosa, v. 32, n. 1, Feb. 2008.

TONEllO, K.C.; CARDOSO, C.A.; DIAS, H.C.T.; SILVA, A.S.; ALVES, M.R.; OLIVEIRA JUNIOR, J.C. Precipitação efetiva em plantio de pinus. Revista da Madeira, p. 118-121, 2004.

TONELlO, K.C.; DIAS, H.C.T.; SOUZA, A.L.; RIBEIRO, C.A.A.S.; FIRME, J.D.; LEITE, F.P. Diagnóstico hidroambiental da bacia hidrográfica da Cachoeira das Pombas, município de Guanhães, MG, Brasil. Revista Ambiente e Água - Na Interdisciplinary Journal of Applied Science, Taubaté, v.4, n.1, p. 156-168, 2009.

VALCARCEL, R. Balanço hídrico no ecossistema florestal e sua importância conservacionista na região ocidental dos Andes Venezuelanos. In: XI SEMINÁRIO SOBRE ATUALIDADES E PERSPECTIVAS FLORESTAIS. Anais... Embrapa, Curitiba, PR. 1984.142p. 